\title{
CIDADE DE DEUS E JANELA DA ALMA: UM ESTUDO SOBRE A CADEIA PRODUTIVA DO CINEMA BRASILEIRO
}

GDADE DE DES AND JANEADAAMA: ASTUDYINIOTHE PRODUCIONOHANINTHE BRAZUANONEMAINDUSIRY

\section{RESUMO}

O bjetiva-se discutir e analisar as trajetórias de produção, comercialização e exibição no mercado interno dos filmes Cidade de Deus e Janela da alma, mapeando convergências e diferenças. Trata-se de estudo de caso múltiplo, de natureza exploratória, com base em triangulação de fontes. Os resultados mostram as seguintes convergências: 0 estreitamento de parcerias entre produtoras e distribuidoras; a utilização de recursos de leis brasileiras de incentivo ao desenvolvimento da atividade audiovisual; a importância e eficácia das estratégias de marketing e de lançamento formatadas; a natureza do trabal ho de equipe dos projetos; e a necessidade de perceber e de superar sinais negativos inicial mente emitidos pelo mercado. Dentre as principais divergências, destacam-se: 0 grau de engajamento dos diretores em todas as etapas dos projetos dos filmes; a focal ização das estratégias de marketing em festivais como forma de desenvolvimento de mercado; e o foco em resultados comerciais.

\section{João Paulo Rodrigues Matta}

Doutorando do Programa Multidisciplinar de Pós-Graduação, Universidade Federal da Bahia - BA, Brasil

jpmatta@terra.com.br

\section{Elizabeth Regina Loiola da Cruz Souza}

Professora da Escola de Administração, Universidade Federal da Bahia - BA, Brasil

beloi@ufba.br

Recebido em 25.09.2008. Aprovado em 13.11.2008.

Avaliado pelo sistema double blind review

Editor Científico: Os organizadores do Fórum

\begin{abstract}
ABSIRACTThe aim is to discuss and analyze production, marketing and exhibition paths in the domestic cinema market of the movies Cidade de D eus and Janela da alma, by outlining their convergences and the differences. This is a multiple case study of an exploratory nature, based on source triangulation. The results show the following convergences: the strengthening of partnerships between producers and distributors; the use of funds from Brazilian legislation for encouraging the development of audio-visual activities; the importance and effectiveness of formatted marketing and launch strategies; the nature of the project team's work and the need to perceive and overcome the negative signals initially coming from the market. The main divergences include in particular: the degree of commitment of the directors at all stages of the films' projects; the focus on marketing strategies in festivals as a way of developing the market and the focus on commercial results.
\end{abstract}

PALAVRAS-CHAVE indústria cinematográfica brasileira, produção, comercialização, Cidade de Deus, Janela da alma. KEMORDS Brazilian movie industry, production, commercialization, City of God, Window of the Soul. 


\section{INTRODUÇÃO}

Embora o mercado cinematográfico brasileiro seja o décimo no mundo em arrecadação e o sétimo em público, não se pode caracterizar o filme brasileiro como autosustentável (KLOTZEL, 2006). Depois da maior crise de sua história no governo Collor (em 1992, o market share, no mercado interno, atingiu o recorde de - 0,05\%), o cinema brasileiro melhorou seu desempenho a partir de 1995. Entre 1997 e 2003, o público subiu de 2,4 miIhões para 22,1 milhões, e sua participação cresceu de $5 \%$ para $21,4 \%$ (MATTA, 2004). N os anos subsequentes, porém, a cinematografia brasileira não conseguiu sustentar o círculo virtuoso de crescimento, reduzindo sua participação no mercado de 21,4\% para 14\% entre 2003 e 2004 , e de $12 \%$ para $11 \%$ entre 2005 e 2006 (FILME $B, 2007)$.

Earp e Sroulevich (2008) afirmam que o mercado de cinema brasileiro ainda não mereceu análises sistemáticas de economistas. José Carlos Durand (2008) destaca a relutância das ciências sociais em reconhecer a lógica dos interesses subjacentes ao mundo da estética. De fato, só mais recentemente a indústria brasileira de cinema vem despertando o interesse acadêmico. Trata-se, assim, de um campo de conhecimento em construção. Glynn (2000) aponta que existe vasta documentação sobre relações conflituosas e ambivalentes na aproximação da produção artística dos elos comerciais. Klotzel (2006, p. 19) considera o cinema o produto audiovisual mais nobre, pelo elevado nível de custos e de elaboração, ou por que é fonte de identificação e emoção, amal gamando o pensamento artístico e cultural com o pragmatismo de interesses comerciais e ideológicos, o que concilia "o pensamento objetivo da indústria com o subjetivo da criação artística".

Earp e Sroulevich (2008) contribuem para essa construção com estudo exploratório sobre as estruturas de mercado da indústria brasileira. Ressal tam que, ao lado da intensa difusão de inovações tecnológicas e organizacionais que barateiam produtos e simultaneamente revolucionam as formas de organização da produção e do consumo, a cadeia de produção do cinema no Brasil caracteriza-se por forte desequilíbrio entre seus el os. 0 elo de produção, marcadamente nacional, reúne uma miríade de produtores, alguns tradicionais e outros entrantes, oriundos da área de propaganda e publicidade. Já no de distribuição, predominam filiais das majors norte-americanas - Disney, Sony, Warner, Fox, Paramount eU niversal - e as brasileiras Europa Filmes e Imagem Filmes. No elo de exibição, as três maiores firmas respondem por mais da metade dos negócios. Sobre o comportamento da demanda, indicam que: (i) existe forte correlação entre o aumento do ingresso e a queda no número deingressos vendidos; (ii) a partir de 1988, há uma queda do preço dos ingressos que precedea recuperação de público; (iii) a partir de 2003, existe uma redução de público que permanece até o presente, o que coincide com a baixa de preços de produtos eletrônicos e a expansão do crédito para tais produtos; (iv) a evolução de público dos filmes brasileiros no mercado nacional não guarda nen huma relação com o preço do ingresso, o que parece sugerir que a demanda pelo filme nativo é função de sua qual idade e do marketing para torná-lo blockbuster (EARP, SROULEVICH, 2008).

Matta (2004) identificou uma melhoria de competitividade dos filmes nacionais no mercado interno de salas de exibição, em razão do crescimento e da manutenção de um fluxo anual de 20 a 30 filmes lançados, com uma distribuição eficiente de grandes companhias estrangeiras que aproveitam 0 incentivo fiscal previsto no art. $3^{\circ} \mathrm{da}$ Lei do Audiovisual. Cita também a importância do aprimoramento da qualidade e a diversidade das produções nacionais, agregadas à integração entre tel evisão e cinema, a partir da criação da Globo Filmes em 1997, além da aproximação entre produção e distribuição via parcerias, que diminui o risco dos lançamentos.

Gatti (2005) constata a transformação dos elos da cadeia cinematográfica no Brasil entre 1993 e 2003, em função de concentração econômica inédita. Co-produções estrangeiras passaram a ditar um melhor desempenho da indústria, via art. $3^{\circ}$ da Lei do Audiovisual, com grupos estrangeiros dominando a distribuição (majors) e a exibição (Cinemark e UCI). Isso sinaliza a internacionalização da economia cinematográfica brasileira, com a desnacional ização do controle do processo econômico do filme nacional.

Fornazari (2006) evidencia que, a partir de 1930, no Brasil, com a intervenção estatal, o cinema deixa de ser atividade regulada apenas por leis de mercado. A brangente, a atuação do Estado se volta para o atendimento a interesses corporativos, a proteção de setores da indústria nacional, a propaganda política ou, ainda, para objetivos educativos e de difusão cultural, acionando instrumentos de fomento e de proteção. Conclui o autor que a intervenção estatal, todavia, não tem sido suficiente para dotar a indústria nacional de condições competitivas equival entes ou próximas às da indústria norte-americana.

Ao focalizar a indústria brasileira de filmes, Kirschbaum (2006) investigou a dinâmica de campos organizacionais com base em abordagem de redes sociais. Seus resultados indicam que os recursos de transformação e capacitação 
para o sucesso do filme predizem melhor sua popularidade do que os recursos mobilizados ou as capacitações para a mobilização de recursos, o que não corrobora os resultados encontrados por Lampel e Shamsie (2003) sobre a indústria de cinema norte-americana. Kirschbaum (2006) explica tal diferença pela baixa exposição dos recursos brasileiros (atores e diretores) no mercado mundial.

Giannasi (2007) destaca a importância do trabal ho em equipe e da sinergia, a dependência com relação à tecnologia estrangeira e a falta de pontos de exibição. Conclui que fal ta um projeto de política cultural e cinematográfica nacional, como há em outros países, e que prevalecem historicamente três problemas: dependência tecnológica, dependência governamental e dominação estrangeira.

Todos os estudos revisados adotam uma abordagem agregada, seja tratando o desempenho da indústria com enfoques inspirados em organização industrial (GIANNASI, 2007; GATTI, 2005), ou porteriana (M ATTA, 2004), seja focando interações entre atores e seus papeis categóricos por meio da análise de redes sociais (KIRSCHBAUM, 2006), ou ainda a evolução dos mercados com base em técnicas quantitativas e estatísticas (EARP e SROULEVICH, 2008), e de políticas públicas de regulação e de incentivo para o setor (FORNAZARI, 2006).

Este artigo adota uma perspectiva mais micro, focada em dois casos particulares. Seu objetivo é discutir a trajetória de produção, comercialização e exi bição, no mercado interno de sal as de exibição, dos filmes Cidade de Deus e Janela da alma, colhendo subsídios para mapear convergências, diferenças e associações entre suas configurações e postulações teórico-empíricas sobre novas formas de organização e capacitação da indústria do cinema.

Lançados em 2002, esses filmes, fenômenos de bilheteria e marcos da retomada do cinema brasileiro, com premiações nacionais e internacionais, são casos ainda não tratados da perspectiva aqui anunciada. Acredita-se que, em momentos de mudanças relativas, perspectivas mais centradas em descrição de casos podem concorrer para elucidar aspectos que não vêm à tona quando são analisadas indústrias, políticas e interações entre atores de forma mais extensiva e quantitativa.

Trata-se de estudo de caso múltiplo, de natureza exploratória, com base em triangulação de fontes, que envolve pesquisa bibliográfica, documental e de campo, com entrevistas semi-estruturadas aplicadas entre 2003 e 2004, realizadas por tel efone com gravação ou por e-mail, com base em roteiros específicos para produção e para distribuição. Sobre Janela da alma foram entrevistados João Jardim, autor do argumento, diretor e produtor, e Bianca de Felippes, sócia da Copacabana Filmes e Produções, a empresa distribuidora. Sobre Cidade de Deus, foram entrevistados Fernando Meirelles, diretor e sócio da 02 Filmes, empresa produtora, Isabel Berlinck, produtora da 02 Filmes, Lamartine Ferreira, assistente de direção, e Anna Luiza M üller e Bruno Wainer, executivos da empresa distribuidora Lumière.

Esteartigo tem cinco partes. A seção seguinte apresenta parâmetros analíticos básicos para o estudo dos casos. $\mathrm{Na}$ terceira e quarta seções, discutem-se, respectivamente, os casos Cidade de Deus e Janela da alma. A síntese dos resultados, as limitações do trabal ho e as possibilidades de estudos futuros constam nas conclusões.

\section{EM BUSCA DE UMA ABORDAGEM PARA O ESTUDO DOS FILMES "CIDADE DE DEUS" E "JANELA DA ALMA"}

Evoluindo da era dos estúdios para a dos pós-estúdios, a indústria norte-americana de filmes, paradigma no mundo, vivenciou expressivas transformações em estruturas de mercado e formas organizacionais. Atual mente, já não é possível dizer se diretores, astros, produção, roteiros, ou a combinação de todos, determinam o sucesso de um filme. Os filmes tornaram-se únicos, e, como tal, sua análise requer a utilização de enfoques e hipóteses concorrentes (LAM PEL e SHAMSIE, 2003).

Como muitos estudiosos da perspectiva da produção cultural focam dados e testes de hipóteses, mais do que a interpretação orientada por uma perspectiva crítica, entende-se que essa pode ser uma abordagem favorável ao alcance dos objetivos deste trabalho exploratório.

No caso da indústria cinematográfica brasileira, a literatura evidencia mudanças em curso nas estruturas de mercado, nas instituições, nos papeis dos atores e em suas interações. Assim, a utilização dessa abordagem pode captar a multiplicidade de estruturas de mercado e de formas organizacionais em co-evolução.

\section{A perspectiva da produção cultural}

Desafiando a ideia dominante de que cultura e estrutura social se refletem mutuamente, inspirada tanto em proposições marxistas quanto funcionalistas, surgiram, nos anos 1970, os primeiros trabalhos sob a perspectiva da produção cultural. Uma revisão de literatu ra realizada por Peterson e Anand (2004) identificou-os em diversas áreas, desde o clássico de Wright Mills, sobre o papel da classe média na cultura americana, até outros que evidenciaram ser o trabalho criativo fruto de esforços cooperativos de um conjunto de participantes, e não de indivíduos isola- 
dos. Outros questionavam teorias que associam mudanças nos campos das artes a transformações sociais revolucionárias ou a pessoas geniais.

A postulação basilar da perspectiva da produção cultural é que a institucionalização de campos de indústrias decorre da combinação de novas tecnologias, novos arranjos legais e novos mercados. Enquanto as leis e regulamentos modelam a evolução de campos de indústrias criativas, a tecnologia viabiliza ferramentas que aumentam a possibilidade de comunicação de pessoas e organizações. Mudanças nessa área tendem a criar novas oportunidades em arte e cultura. Os mercados são frutos das ações de produtores em busca de compreender e de atender aos desejos dos consumidores. As organizações do campo cultural modelam suas ações para criar produtos culturais que atendem às expectativas dos consumidores.

Essa definição de mercado não contradiz a de Poldony (2001), citada por Peterson e Anand (2004), segundo a qual os mercados são redes com dois fluxos básicos: um de sinalização, que legitima e dá credibilidade a um conjunto particular de produtos ofertados, eoutro sinalizador, em que os produtos e serviços são replicados em outros mercados. N esse sentido, os mercados não são entidades abstratas, moldadas à revelia de normas sociais e simbólicas, mas frutos da combinação histórica de elementos econômicos e não-econômicos. Não são formados por agentes homogêneos e maximizadores de funções objetivas, nem o sistema de preços é portador do conjunto de informações necessárias à decisão dos agentes econômicos (HERSCOVICI, 2007).

Ao conjunto de forças da dinâmica da indústria de cinema atual, que abrange leis, regulamentos, tecnologia e mercados, somam-se três elementos: estrutura industrial, organizacional e ocupacional. Com o predomínio da busca de sinergia e de estratégias padronizadas para a produção de um mix de produtos inter-relacionados (livros, filmes, vídeos e brinquedos), um pequeno número de grandes corporações progressivamente passa a dominar a indústria. Atualmente, para acessarem os benefícios de estruturas simples, el as se reorganizam em muitas unidades independentes, ou simplificam controles para favorecer estilos de liderança empreendedores (PETERSON e AN AND, 2004).

A cada campo cultural vincula-se um sistema peculiar de carreiras, e as redes desenvolvidas pel os trabal hadores "criativos" dão suporte às "culturas de produção". Esse sistema peculiar de carreiras é articulado por agenciadores de talentos (gatekeepers) (PETERSON e ANAND, 2004). Inicialmente interiorizados em estruturas hierar- quizadas, tais recursos se exteriorizaram com o passar do tempo - ao lado do aumento de importância da fase de pré-produção, a fusão de papéis entre diretor e produtor e a consolidação de novos papéis e atores - formando: 0 agenciador de talentos, as redes de provedores de recursos financeiros e os produtores independentes (LAM PEL e SHAM SIE, 2003). Peterson e Anand (2004) sugerem que as seis dimensões (leis e regulamentos, tecnologia, mercado, estrutura industrial, estrutura organizacional e estrutura ocupacional) parecem tão interconectadas, que uma mudança significativa em uma delas pode desencadear um ciclo de desestabilização e de reorganização em todo o campo.

\section{A evolução da indústria norte-americana de cinema}

A perspectiva da produção cultural, segundo Peterson e Anand (2004), busca respostas a quatro grandes problemas de pesquisa: (i) Como as teorias de gerenciamento têm evoluído no tempo? (ii) Que processos institucionais guiam a decisão em ambientes ambíguos? (iii) Como as redes organizacionais promovem a produção simbólica? (iv) Qual a dialética entre organizações especialistas e generalistas na produção de mercados? Nos trabal hos revisados por Peterson e Anand (2004), destacam-se os que mostram que geração, difusão e absorção de inovações requerem o processamento sistemático de símbolos, a realização de negociações entre proponentes, usuários e apoiadores, e demonstrações de sua eficiência nos estágios iniciais de utilização para viabilizar sua difusão, que se mantém em estágios avançados com base em popularidade.

Quanto aos mecanismos institucionais, há dois temas básicos na resposta a essa questão. 0 primeiro é que, em contextos de incerteza, produtores de artefatos culturais lançam mão da imitação e de ligações a atores e instituições legitimados para a aceitação de seus trabalhos. 0 segundo aponta que as lógicas predominantes em uma esfera institucional governam o processo decisório em qualquer tempo e resultam na produção de um determinado artefato cultural em detrimento de outros.

Referente às redes organizacionais, a produção pode ocorrer dentro de redes fortemente conectadas, em círculos de produção e "grupos de profissionais invisíveis". Peterson e Anand (2004) citam Faulkner e Andersen (1987), revelando que o núcleo central (core) da rede de produção de Hollywood correspondia a $10 \%$ de todos os produtores, que respondiam por $38 \%$ de toda a produção da indústria, de mais de 2.400 filmes realizados entre 1965 e 1980. Adicionalmente, os produtores de sucesso tendem a compor um pequeno mundo de indivíduos 
fortemente unidos, enquanto a periferia é mais aberta e permeável à participação de indivíduos qualificados, recursos e capital. As redes de produção, restritivas por natureza, caracterizam-se por atividades de rotinas e de descoberta que influenciam a produção de inovações e, simultaneamente, sofrem a influência de produtos culturais inovadores, embora possam também constituir obstáculos a mudanças.

No que diz respeito às organizações especialistas e generalistas, o fato de as firmas produtoras serem especial istas ou generalistas e o tipo de produto oferecido condicionam as mudanças nas indústrias culturais (PETERSON e ANAND, 2004).

Por pressões regulatórias, ao final da década de 1960 , recursos de estúdios norte-americanos, hierarquizados e vertical mente integrados, foram exteriorizados e al ocados em mercados. Estúdios tornaram-se elos de financiamento e de distribuição, com papel-chave na reunião dos recursos captados em redes de provedores de capitais, junto a agenciadores de talentos e a produtores independentes. Recursos reunidos e acordos de distribuição firmados avançam na fase de produção. Lampel e Shamsie (2003) postulam que o centro gerador de vantagem competitiva deslocou-se para os atributos dos filmes em si, em visão concorrente à de Peterson e Anand (2004) , com as transformações no sistema de produção seqüencial para o sistema "por projeto". Registraram-se mudanças substantivas no modus operandi, com destaque para a emergência de novas formas de organização de sistemas de produção, de estruturas de carreiras, de leis e regulamentos e de mercados, além de redução de overhead.

A operação por projetos é processo complexo e interconectado de negociações, que envolve simultaneamente amplo conjunto de firmas e de indivíduos. Implica fortes pressões com vistas à identificação, experimentação e difusão de novas rotinas e práticas, aumentando a importância da capacidade de mobilização de recursos, fator condicionante do sucesso de filmes e, paral el amente, declinando a importância das capacitações de transformação (LAM PEL e SHAM SIE, 2003).

\section{O CASO "CIDADE DE DEUS"}

Esse é um dos filmes mais importantes produzidos no Brasil. Premiações nacionais e internacionais e quatro indicações para o Oscar 2004 respaldam seu mérito. Comercialmente, foi o primeiro filme brasileiro, na retomada, a romper a barreira dos 3 milhões de espectadores, tendo alcançado grande público no exterior.

\section{0 nascimento do projeto, sua pré-produção e a dinâmica da produção}

Fernando Meirelles, diretor de Cidade de Deus, inspirou-se em romance homônimo de Paulo Lins sobre o cotidiano da favela Cidade de Deus, no Rio de Janeiro. M eirelles diz que, após concluir a leitura, já estava decidido a fazer 0 filme. Comprou os direitos da obra e contratou o roteirista Bráulio Mantovani para adaptar, com ele, o denso romance, de 600 páginas e 252 personagens, num roteiro de cerca de duas horas de projeção.

Segundo M eirelles, o foco da adaptação foi a fidelidade "ao espírito do livro", mas não à sua estrutura narrativa. O protagonista Busca-Pé, "observador-narrador que não participa da ação, mas está sempre sujeito a ela", não existia no romance. Houve exclusão e fusão de personagens. A té o início das filmagens e ao longo da produção, o roteiro evoluiu, foi enxugado, sob influência não só do diretor e do roteirista, mas de outros profissionais da produção e dos atores. Até a conclusão da película, houve 12 versões do roteiro (MANTOVANI, MEIRELLES e MÜLLER, 2003).

Como diferencial da produção de Cidade de Deus, destacam-se a seleção, a preparação e a performance dos atores. Meirelles optou por trabalhar com atores não-profissionais, envolvidos com a realidade das favelas cariocas. Em meados de 2000, sob a coordenação de Kátia Lund, iniciou-se o processo de seleção de atores em comunidades de baixa renda, com a realização de 2 mil entrevistas.

N os meses seguintes, 200 atores amadores sel ecionados foram treinados por profissionais especializados na oficina Nós do Cinema, sem saberem que essa era uma preparação para o longa-metragem. Dirigida por M eirelles e Kátia Lund, a realização do curta-metragem para a TV, Palace II (baseado em histórias do livro de Lins não aproveitadas no roteiro de Cidade de D eus), encerrou a oficina. 0 episódio, encomendado pela Rede Globo para a série Brava Gente, acabou funcionando como um laboratório antes da pré-produção do longa-metragem. $\mathrm{N}$ a filmagem de seis dias, na comunidade de Cidade de Deus, consolidou-se o entrosamento de equipe e el enco.

Na pré-produção, iniciada em fevereiro de 2001, quase todos os atores da oficina foram recrutados. Ao todo, foram mais de 70 atores, principais e coadjuvantes, e cerca de 150 atores secundários, além de 2.600 figurantes, a maior parte crianças e adolescentes. Do elenco principal, apenas M atheus $\mathrm{N}$ achtergaele era ator profissional.

Durante os ensaios, a preparadora de elenco Fátima Toledo aprofundou as relações entre os personagens e as 
emoções de cada cena. 0 processo de preparação foi crucial para o nível de improvisação que aconteceu nas filmagens. N achtergaele, ator consagrado, passou pelo mesmo processo de preparação, "para não inviabilizar o projeto", segundo Lamartine Ferreira, assistente de produção.

As filmagens foram realizadas em nove semanas, de 19 de junho a 21 de agosto de 2001, em locações diferentes. 0 processo de montagem, com Daniel Rezende, durou cerca de cinco meses. Fernando M eirelles credita a qualidade do resultado final a toda a equipe, especialmente à performance dos atores e às contribuições de Kátia Lund, Bráulio Mantovani, César Charlone, Daniel Rezende e Tulé Peake.

Merece destaque na produção, o envolvimento e a obstinação de Meirelles na realização do projeto. 0 diretor não poupou esforços e investiu recursos próprios e de sua produtora, a começar pela compra dos direitos do romance de Paulo Lins. Além disso, foi estratégica a aproximação com a Rede Globo, que facilitou o arranjo com a distribuição.

A narrativa de nascimento, pré-produção e produção do projeto evidencia aspectos abordados na revisão de literatura e do estado de campo. Trata-se de produção "por projeto", que envolveu um criativo e sinérgico trabalho de equipe, bem como capacidade de mobilização e articulação de recursos para assegurar a execução, incluindo-se a aproximação da Globo. Além disso, o diretor emerge dos novos quadros da retomada, ligados a agências de propaganda e publicidade (EARP eSROULEVICH, 2008; GIANN ASI, 2007; LAMPEL e SHAM SIE, 2003).

Em conformidade com a literatura revisada, verificase a fusão de papeis de diretor, produtor e investidor (PETERSON e ANAND, 2004). Além disso, a preparação do curta para a Globo, assim como o envolvimento da produtora Vídeo Filmes (do diretor Walter Salles), ainda antes da pré-produção, podem ser consideradas estratégias de busca de âncoras em players já legitimados no mercado. Essas conexões foram decisivas para trazer a Lumière para o projeto, o que foi articulado, em primeira instância, pela Vídeo Filmes, parceira daquela distribuidora desde o filme Central do Brasil (1998). Kirschbaum (2006) afirma que os recursos de transformação e as capacitações de transformação de recursos predizem melhor a popularidade do filme do que os recursos mobilizados. Como este é um estudo de caso, não se pode contestar essa afirmação, mas a análise de sua narrativa aponta claramente para a importância das capacitações de mobilização e de articulação para o sucesso de Cidade de Deus, conforme enunciado por Lampel e Shamsie (2003).

\section{0 arranjo entre produção e distribuição}

Ao ser questionado se interesses comerciais influenciaram a ideia e a realização de Cidade de Deus, Meirelles respondeu: "Fui movido inteiramente pela história, seu contexto e seus personagens. Jamais achei que o filme poderia fazer o sucesso comercial que fez. Foi integralmente do coração para a tela. Comercial e estrategicamente era um erro total".

Meirelles, sócio de uma produtora bem-sucedida no mercado publicitário, empenhou-se na realização de um projeto cinematográfico ousado, inovador e de al to risco, preocupado mais com a qualidade dos resultados do que com o potencial de retorno comercial. 0 diretor e sua produtora mobilizaram, captaram e articularam recursos de transformação, de financiamento, de divulgação e de distribuição para real izá-lo. Esse conjunto de capacitações assegurou tanto a qualidade quanto 0 acesso a canais de peso de distribuição. Entretanto, a fal ta de experiência em negociação de contratos com grandes redes de distribuição não conduziu à formatação do arranjo entre produção e distribuição de modo a remunerá-los de acordo com o grande lucro gerado pel o filme. Houve fal has de capacitações em negociações de contratos, apesar dos rendimentos indiretos, sobretudo para Fernando Meirelles, que teve sua carreira internacionalizada a partir de então, o que minimiza 0 aspecto apontado por Kirschbaum (2006) de pouca exposição dos players locais ao mercado mundial. A pós Cidade de D eus, M eirelles já dirigiu duas produções internacionais: 0 jardineiro fiel (2005) e Ensaio sobre a cegueira (2008). Para ele,

Financeiramente o filme foi o pior negócio que fiz em minha vida. Como investi meu dinheiro pessoal no projeto, levado pelo entusiasmo, quando consegui que a Miramax e a Wild Bunch me devolvessem o que havia gastado, me dei por satisfeito. Assinei os contratos que puseram na minha frente. 0 filme deve chegar a 25 milhões de dólares neste ano e até agora não recebi um centavo sequer. E nem vou receber. Só não fico mais chateado com isso, porque este investimento que fiz me colocou no mercado internacional com um patamar de cachê que compensa as perdas.

Dos R $\$ 7$ milhões que custearam a produção de Cidade de Deus, $R \$ 5,5$ milhões foram investidos pela 02 Filmes e $\mathrm{R} \$ 1,5$ milhão foram provenientes das leis de incentivo. Sabe-se que parte do R $\$ 1,5$ milhão veio do art. $3^{\circ}$ da Lei do Audiovisual, o que possibilitou à Lumière tornar-se co-produtora e detentora dos direitos exclusivos de distribuição no Brasil (SOUZA, 2003). Tais dados corroboram 
a importância das leis de incentivo e das políticas de governo para fomento à produção cinematográfica no Brasil, conforme apontam M atta (2004), Gatti (2005), Fornazari (2006) e Earp e Sroulevich (2008).

Segundo Bruno Wainer, da Lumière, as negociações entre agentes de produção e de distribuição foram extremamentecomplexas, envolvendo parceiros internacionais (Wild Bunch e Miramax), várias mídias em vários países, compensações cruzadas de receitas etc. As negociações entre M eirelles e a Lumière começaram ainda na fase de preparação do el enco, e os contratos só ficaram prontos com o filme praticamente terminado (no segundo semestre de 2001). 0 arranjo definitivo entre produção e distribuição estabeleceu que a produção seria, principalmente, da $\mathrm{O} 2$ Filmes e da Vídeo Filmes; a co-produção, da Lumière, da Wild Bunch e da Globo Filmes; a distribuição exclusiva no Brasil ficou com a Lumière; os direitos de distribuição nas Américas ficaram com a Miramax; e a Wild Bunch assumiu ainda o papel de agente internacional de vendas nos continentes não explorados pela Miramax.

A Globo Filmes fechou a co-produção durante as filmagens, em meio ao sucesso de audiência de Palace II, na série Brava G ente. A confirmação de parceria com a Wild Bunch e a Miramax, antes da conclusão do filme, garantiu, com antecedência, o seu lançamento em mercados internacionais - fato inédito na retomada, segundo Almeida e Butcher (2003). No processo de negociação, o prestígio internacional conquistado pela Vídeo Filmes com Central do Brasil (1998) e Abril despedaçado (2001) teve um papel importante. $O$ fato é que a Wild Bunch ea Miramax acreditaram no potencial de mercado do filme antes mesmo que ele fosse finalizado.

O sistema de produção "por projeto", com recursos desvertical izados e complexos, emerge da descrição do arranjo definitivo estabelecido entre produção e distribuição. A complexidade operacional corrobora a complexidade descrita na revisão da literatura, derivada da exteriorização dos recursos na era pós-estúdio da indústria cinematográfica norte-americana, que transforma cada filme em um projeto que envolve uma multiplicidade de recursos disponíveis no mercado, muito disputados, cuja captação requer um processo complexo de negociações com um amplo conjunto de firmas e indivíduos. Reitera-se a importância de atores legitimados, no caso a Globo Filmes e a Vídeo Filmes, na redução de riscos de não finalização dos projetos (LAM PEL e SHAMSIE, 2003).

\section{Estratégias de marketing e de lançamento}

A articulação entre produção e distribuição se deu ainda no processo de realização. A aproximação foi consumada pelo fato de a Lumière ter se tornado coprodutora e adquirido os direitos de distribuição exclusivos do filme no Brasil, por meio do art. $3^{\circ}$ da Lei do Audiovisual.

Finalizado o filme e resolvidas questões contratuais, iniciou-se a formatação das estratégias de lançamento. Um elemento fundamental foi a presença da Globo Filmes como co-produtora, possibilitando o acesso aos mais sofisticados e eficazes canais de divul gação. Segundo M eirelles, as estratégias de lançamento ficaram a cargo de Bruno Wainer (Lumière) e Daniel Filho (Globo Filmes), acompanhadas pela 02 Filmes. Quanto aos resultados do Iançamento, M eirelles afirma que

O filme foi bem lançado [ ...] deixei todas as decisões estratégicas por conta da Lumière e do Daniel Filho [...] Esse é o negócio deles e não o meu. Não posso reclamar de nada depois do desempenho do filme. Faria da mesma forma, isso é, deixaria nas mãos deles.

Conforme Bruno Wainer, não houve estratégias prévias de divulgação, já que não se tinha uma ideia concreta do potencial de mercado do filme. Porém, quando ele ficou pronto e foi apresentado à distribuidora, houve a certeza de que o filme constituía um momento especial da cinematografia brasileira. Diante de sua experiência de mais de 200 filmes comercializados pela Lumière, quando assistiu a Cidade de Deus, Wainer "acreditou estar diante de um marco histórico".

Seguindo procedimento padrão, a Lumière partiu para exibições-teste para perfis diferentes de público. Diante das reações, delinearam-se as estratégias. Houve, em geral, uma resposta positiva, apesar da violência da trama. Parte da crítica de cinema revelou uma tendência a desprezar o filme, pela utilização de "linguagem publicitária" e espetacularização da violência, revel ando relações conflituosas e ambivalentes entre arte e negócios (GLYN N, 2000). Frente a esse debate, a distribuidora ampliou seu foco, direcionando-o para os temas violência e tráfico de drogas, muito presentes na vida dos moradores das favel as cariocas e dos brasileiros em geral. Realizaram-se sessões especiais para políticos, já que 0 ano de lançamento era também de eleições presidenciais. 0 candidato do PT à presidência, Luiz Inácio Lula da Silva, participou de uma dessas sessões, passando a citá-lo em debates. Como já havia sido feito no lançamento de Central do Brasil (1998), a distribuidora promoveu sessões gratuitas. Cerca de 30 mil pessoas assistiram ao filme antes de ser vendido 0 primeiro ingresso.

Enfim, buscou-se criar uma imagem nobre do filme em 
função de sua temática e, com isso, sufocar ou diminuir a importância de um debate sobre a linguagem cinematográfica. 0 trágico assassinato do jornalista Tim Lopes, próximo ao lançamento, acabou criando maior discussão em torno do tema. Novamente verifica-se a importância, para o sucesso do filme, de atores-âncoras já legitimados, sobretudo nessa fase, envolvendo-os nas estratégias de marketing (LAMPEL e SHAMSIE, 2003). A partir desses atores, desencadeou-se um fluxo de sinalização de mercado que legitimou o filme, dando-Ihe credibilidade (PETERSON e ANAND, (2004).

Para minimizar o peso da crítica à linguagem do filme, a Lumière decidiu que Cidade de Deus não participaria de festivais de cinema no Brasil, estratégia reforçada pela seleção do filme para participar do Festival de Cannes no primeiro semestre de 2002, antes do lançamento no Brasil.

O filme foi lançado em 30 de agosto de 2002, no auge da campanha presidencial, conforme resolveu a Lumière, para potencial izar os resultados das estratégias de minimizar a crítica negativa à linguagem e deslocar a discussão para a problemática: a violência nas favelas do Brasil. A campanha de lançamento teve forte suporte de mídia por parte da Rede Globo, envolvendo crossmedia, referências em novelas, programas e telejornais.

A definição quanto ao número de cópias foi negociada entre a distribuidora e Fernando M eirelles. Segundo Bruno Wainer, enquanto a Lumière, pensando na mídia que o filme já possuía e na que a Rede Globo iria colocar, propôs 150 cópias para al cançar uma bilheteria de cerca de 1 milhão de espectadores, M eirelles se mostrou mais cauteloso, propondo apenas 30 cópias. Acabou prevalecendo um meio termo: 100 cópias. Porém, diante da resposta do público, foram feitas mais cópias: na 2a semana, já havia 120 cópias em exibição, chegando a 180 cópias na 6a semana.

0 resultado comercial de Cidade de Deus surpreendeu toda a equipe, inclusive a Lumière. Com um público total de 3.307.746 espectadores, o filme teve mais espectadores do Rio de Janeiro e de São Paulo, que responderam por $38 \%$ do total, ficando em exibição por mais de 35 semanas, contra uma média de 16 semanas nos outros estados do Brasil (FILME B, 2004).

A indicação para Cannes, a estratégia de marketing da Lumière e da Globo, com a utilização de crossmedia, a distribuição extensiva de entradas gratuitas e a promoção de sessões para públicos especiais, em particular políticos, concorreram para o sucesso da fita, que, semana a semana, ocupava mais salas e conquistava mais público. Em sua 9ạ semana de exibição, permanecia em 178 salas e com público semanal próximo a 250 mil pessoas. N em os blockbusters Sinais e Scooby-D 0o, lançados no mesmo período, foram capazes de tirar-Ihe espaço.

Para Bruno Wainer, se tivesse obtido o prêmio em Cannes, o filme poderia ter chegado à casa dos 4 milhões de espectadores. Concluiu que Cidade de D eus foi um filme "muitíssimo bem-sucedido comercialmente" eque trouxe muito lucro para a Lumière, não só nas bilheterias, como também na venda de DVDs e vídeos. Segundo a Lumière, até abril de 2004, entre rental e sell-trough, tinham sido comercializadas 80 mil peças, de ambos os formatos. Também essa trajetória corrobora resultados de pesquisas, antes comentados, sobre a crescente importância de outras janelas de exibição no sucesso comercial dos filmes (MATTA, 2004; EARP e SROULEVICH, 2008).

\section{O CASO "JANELA DA ALMA"}

Desde a virada do milênio, houve crescimento no volume de produção e no desempenho de bilheteria de documentários brasileiros, com alguns filmes chegando a superar ficções em freqüência de público. Janela da alma constitui-se num desses fenômenos, rompendo a marca dos 100 mil espectadores.

\section{0 nascimento do projeto, sua pré-produção e a dinâmica da produção}

Segundo João Jardim, produtor e diretor, o documentário Janela da alma surgiu da seguinte indagação: "Como problemas de visão interferem na personalidade e na vida de cada um?". Essa pergunta acompanhou-o desde menino, já que, devido à miopia, passou a usar óculos aos 4 anos de idade. Com o tema e o argumento definidos, Jardim convidou o fotógrafo Walter Carvalho (co-diretor do filme, usuário de óculos desde os 12 anos) para desenvolver o projeto. A produtora foi a Ravina Filmes, cujo proprietário, Flávio Tambellini, participou desde 0 início do projeto-filme. Trata-se também de projeto-filme realizado em equipe.

A pré-produção foi iniciada em setembro de 1999. Em função da agenda dos entrevistados, as filmagens foram real izadas em três etapas, com locações no Brasil, Europa e EUA. Ao todo, realizaram-se 50 entrevistas, com cerca de 30 horas de filmagens, reduzidas a 19. Entre ideia, finalização e lançamento, decorreram três anos, com a finalização da primeira cópia em junho de 2001.

A realização absorveu um orçamento total de $\mathrm{R} \$ 900$ mil (R $\$ 700$ mil para a produção e R $\$ 200$ mil para o lançamento), quase total mente coberto com recursos captados 
via leis de incentivo. Diante do caráter "estranho", inovador e do baixo apelo comercial do projeto, cerca de três anos se passaram até que se conseguissem os $50 \%$ do valor orçado para a produção e ela fosse iniciada. 0 restante dos recursos foi sendo captado com o trunfo da exibição para investidores de trechos do trabal ho já realizado. 0 caso de Janela da alma evidencia maior dificuldade de captação de recursos financeiros, provavel mente em função de menor articulação da equipe com grandes players, além do ineditismo da proposta. A estratégia de exibição de trechos já executados do filme para conquistar novos financiadores mostra-se coerente com o pontuado na revisão: 0 lançamento de inovações requer negociações simbólicas entre proponentes, apoiadores e usuários (PETERSON e AN AND, 2004). Também nesse caso verifica-se a importância das leis de incentivo (MATTA, 2004; FORNAZARI, 2006; EARP e SROULEVICH, 2008).

\section{0 arranjo entre produção e distribuição}

Conforme João Jardim, do nascimento da ideia à transformação em filme, houve a preocupação com a viabilidade de mercado e a potencialização de espectadores. Já na produção, em meio à seleção dos entrevistados, ou diante da preocupação em destinar parte dos recursos captados para a campanha de lançamento, percebem-se tais preocupações. Bianca Felippes, sócia da Copacabana Filmes, deixou claro o quanto foi importante, para o desempenho de mercado al cançado, o envolvimento direto de seu realizador na formulação das estratégias e planos de lançamento, inclusive garantindo a destinação de expressiva parte dos recursos captados para essa fase. Em comparação com o caso anterior, o procedimento do diretor é diferenciado, o que pode lhe ter proporcionado a consolidação de capacitações inovadoras, denotando uma perspectiva comercial mais aguçada do que a de Meirelles.

Concluída a primeira cópia do filme, em junho de 2001, passou-se à campanha de lançamento. Como a distribuidora e os agentes da produção acreditavam na qual idade do filme, decidiram adotar a estratégia de difusão favorável boca a boca, para ajudar a superar possíveis resistências à temática incomum. Para isso, foi fundamental a participação do filme em mostras e festivais, com premiações importantes: em 2001, no F estival do Ceará; na Mostra BR de Cinema de São Paulo, do júri popular; e de melhor filme no Festival de Cinema Brasileiro de Paris. Esses dados confirmam a importância apontada na literatura dos fluxos de sinais emitidos por especialistas para a conformação de mercados de cinema (PETERSON e ANAND, 2004).
As premiações reforçaram a difusão boca a boca, gerando mídia espontânea em diversos meios de comunicação, o que contribuiu para atrair a atenção de um público intelectualmente mais exigente (o nicho de mercado dos documentários). Cresceram convites para João Jardim participar de palestras e debates no meio acadêmico, em rodas psicanalíticas, o que era articulado pela distribuidora. N essas oportunidades, realizavam-se negociações simbólicas entre o proponente do filme e a audiência, o que impactava positivamente o mercado do filme (PETERSON e ANAND, 2004). Tudo isso foi chamando a atenção de proprietários de cinemas, em especial do circuito de salas de arte e de salas de rua, o que, segundo Bianca de Felippes, favoreceu as negociações para o lançamento.

\section{Estratégias de marketing e de lançamento}

O lançamento nos cinemas brasileiros ocorreu em junho de 2002, com um total de cinco cópias. Não houve grande esforço publicitário, diante da dimensão reduzida do lançamento e da limitação de recursos, registrando-se, no entanto, apuro na preparação e distribuição prévia de cartazes e do trailer de divulgação. 0 período escolhido para a comercial ização coincidiu com o megalançamento do blockbuster 0 homem aranha, a maior bilheteria do ano, o que acabou sendo vantajoso, já que houve uma queda no número de lançamentos no período - diante do receio de enfrentar aquele filme. Esse fato proporcionou mais espaço de exibição a Janela da alma também no circuito comercial, o que complementou a programação em complexos de salas, com vistas a atender um nicho de mercado diferenciado. A parentemente, observa-se que a segmentação de mercado de cinema não é levada em consideração pelos elos mais oligopolizados e internacionalizados da cadeia cinematográfica no Brasil, pelas suas distribuidoras e pelas salas padrão de exibição, os quais preferem replicar produtos e estratégias de sucesso, conforme também se aponta na revisão de literatura (PETERSON eANAND, 2004).

Nos três primeiros meses de exibição, as cinco cópias lançadas tiveram desempenho surpreendente para um documentário. Sua exibição concentrou-se inicialmente em São Paulo, onde, ainda sob o glamour do prêmio conquistado no ano anterior, o filme conseguiu estrear na maior sala do circuito Unibanco (Arteplex), chegando, depois, a uma grande sala do Rio de Janeiro, sob influência dos números obtidos em São Paulo. 0 desempenho de bilheteria, nas primeiras semanas, mostrou o potencial do filme, gerando crescente difusão boca a boca. A Copacabana Filmes, por sua vez, impulsionava esse pro- 
cesso, coordenando a agenda de palestras e promovendo sessões especiai s. A estratégia boca a boca e de participação do diretor em palestras e seminários concretiza momentos de negociações entre proponentes e usuários, necessárias em estágios iniciais de lançamento de inovações. A difusão posterior já se al imentava dos resultados dessa negociação inicial de símbolos e se nutria da popularidade que, paulatinamente, o filme ia conquistando (PETERSON e ANAND, 2004).

O desempenho nas salas de exibição fez aumentar a demanda por cópias de exibidores de outras grandes cidades, como Salvador, Recife e Brasília. Como as primeiras cinco cópias se mantiveram presas em cinemas do Rio de Janeiro e São Paulo, a Copacabana Filmes fez mais sete cópias financiadas com receita dos primeiros meses de exibição. 0 filme já havia conquistado vida própria, o que é coerente com a literatura que ressalta a manutenção da difusão em estágios avançados, com base na popularidade da inovação em si (PETERSON e ANAND, 2004).

A trajetória de exibição de Janela da alma abarcou principalmente salas de arte e salas de rua, e, em muitas delas, o filme permaneceu em cartaz por três ou até quatro meses, o que foi fundamental para o seu desempenho. Por períodos mais curtos, também foi exibido em complexos, multiplex e salas de shoppings, conseguindo atingir também um público fora de seu nicho de mercado. 0 filme havia conseguido superar resistências de diferentes faixas de público, projetando-se para além de suas fronteiras prováveis e abrindo mercado para os documentários em geral. Tal narrativa evidencia como as estratégias adotadas de negociação de símbolos entre produtores e usuários foram eficazes (PETERSON e ANAND, 2004).

0 desempenho de mercado de Janela da alma surpreendeu a todos. João Jardim comentou que sua expectativa inicial era que o filme fizesse 20 mil espectadores. A distribuidora, de acordo com depoimento de Bianca de Felippes, projetou inicialmente 50 mil espectadores e, ao longo da exibição, ampliou para 100 mil. Ambas as projeções falharam: o documentário alcançou 144 mil espectadores, mais de $60 \%$ desse total no Rio de Janeiro e em São Paulo, repetindo a trajetória do caso anterior. Conforme Filme B (2003), a média de tempo de permanência de Janela da alma em cartaz nos cinemas foi de 26 semanas.

N ão houve prejuízo, já que a produção e a distribuição foram quase inteiramente financiadas pel as leis de incentivo. Os quase $\mathrm{R} \$ 800$ mil de receita foram divididos entre a produção (25\%), a distribuição (25\%) e os exibidores
(50\%). Dos dados apresentados, pode-se inferir que os ganhos da produção e da distribuição foram equival entes a cerca de R\$200 mil para cada, descontados os custos do investimento nas sete cópias extras. Da perspectiva de retorno financeiro, também esse caso se mostra diferente do anterior, uma vez que a produção foi ben eficiada e não só a distribuição e os exibidores.

De modo similar ao caso anterior, o sucesso de Janela da alma abriu mercados para o filme também em janelas de exibição secundárias. Segundo João Jardim, até março de 2004 já haviam sido vendidos 2 mil DVDs e 800 vídeos, distribuídos pela Europa Filmes. Ainda em 2004, o filme foi negociado para exibição em canal de TV por assinatura (GNT - Globosat), com uma audiência média adicional de mais 46 mil pessoas, colocando o canal em quarto lugar no horário. Essa trajetória corrobora resultados de pesquisa que apontam a crescente consolidação de outras janelas de exibição no Brasil (MATTA, 2004; EARP e SROULEVICH, 2008).

\section{CONCLUSÕES}

Para concluir, retoma-se o objetivo geral deste artigo em duas questões de pesquisa: Que convergências e divergências emergem da análise das trajetórias dos casos Cidade de Deus e Janela da alma? Que convergências existem entre essas trajetórias e as postulações da literatura revisada?

Quanto às convergências, percebem-se: o estreitamento de parcerias entre produtoras e distribuidoras para 0 desempenho de mercado, para a utilização de recursos exteriorizados no mercado e para a redução de riscos; a utilização de recursos de leis de incentivo ao desenvolvimento do audiovisual; a importância e eficácia das estratégias de marketing e de lançamento formatadas; a natureza de projeto em equipe; a necessidade de superar sinais negativos inicialmente emitidos pelo mercado; a vinculação dos diretores a agências de publicidade; o sucesso de público; e a geração de novas oportunidades para os dois diretores, consolidando seus papeis no mercado nacional e projetando-os internacionalmente.

As principais divergências detectadas ligam-se: ao grau de engajamento dos diretores em todas as etapas dos projetos; à focalização das estratégias de marketing em festivais, como forma de desenvolvimento de mercado; e ao foco em resultados comerciais. No caso de Cidade de Deus, Fernando Meirelles afirmou não ter focalizado sua preocupação no resultado comercial e ter deixado a questão das estratégias de marketing e de lançamento a 
cargo de seus parceiros, que decidiram não usar os festivais nacionais para abrir mercado. Já o diretor de Janela da alma foi ator-chave na formulação e implementação de tais estratégias, sempre focou o resultado comercial e utilizou, ao lado de outras, a estratégia de participação em festivais brasileiros para desenvolver o mercado.

Quanto às convergências entre essas trajetórias e as postulações da literatura revisada, exploramos essa questão ao longo da análise dos dois casos, sendo que, de forma sucinta, verifica-se que a difusão de produtos inovadores envolve negociação simbólica e o recurso a atores já legitimados no mercado. Por outro lado, há fusão de papeis profissionais. Ainda, percebe-se a importância das capacitações de mobilização de recursos, haven do complexidade das estruturas de mercado da indústria cinematográfica, com a participação de grandes e pequenos players ao lado de indivíduos. Finalmente, observa-se o desbalanceamento da cadeia de produção de cinema no Brasil, bem como o achatamento do overhead do elo de produção nacionalizado.

Para concluir, chama-se a atenção para as limitações desta pesquisa. Ao definir como foco o mercado de salas de cinema, não se investigou a trajetória dos filmes em mercados secundários, como a TV aberta, por assinatura, ou a locação e compra de DVDs. Outra limitação foi a escol ha de dois casos de sucesso, o que pode enviesar a compreensão do fenômeno investigado. Em vista dessa outra limitação e na perspectiva de acumulação de conhecimentos que possam levar ao fortalecimento da abordagem da perspectiva de produção cultural, sugerese a realização de pesquisas intensivas e extensivas, incluindo casos de sucesso e de insucesso.

\section{REFERÊNCIAS}

ALMEIDA, P. S; BUTCHER, P. Cinema: desenvolvimento e mercado. Rio de Janeiro: Aeroplano, 2003.

DATABASE BRASIL 2003 - Números e Informações sobre Cinema no Brasil: Filme B, 2004. 1 CD-CARD.

DATABASE BRASIL 2007 - Números e Informações sobre Cinema no Brasil: Filme B, 2007. 1 CD-CARD.

DURAND, J. C. Prefácio. In BENhAMOU, F. Economia da cultura. São Paulo: Ateliê Editorial, 2007.
EARP, F; SROULEVICH, H.O mercado de cinema no Brasil. In EARP, F.; SROULEVICH, H.; SOUZA, R. G. Dois estudos sobre economia do cinema no Brasil. TD 0002/2008. (Série Textos para Discussão).

FORNAZARI, F. K. Instituições do Estado e políticas de regulação e incentivo ao cinema no Brasil. RAP, Rio de Janeiro, v. 40, n. 4, jul./ago. 2006, p. 647-677.

GATTI, A. Distribuição e exibição na indústria cinematográfica brasileira (1993/2003). Campinas: Universidade Estadual de Campinas, 2005. p. 357.

GIANNASI, A. M. 0 produtor e o processo de produção dos filmes de longa metragem brasileiros. São Paulo: ECA-USP, 2007. p. 112.

GLYNN, M. A. When cymbals become symbols: conflict over organizational identity within a symphony orchestra. Organization Science, v. 11, n. 3, p. $285-298,2000$.

HERSCOVICI, A. Capital intangível e direitos de propriedade intelectual: uma análise institucionalista. Revista de Economia Política, v. 27, n. 3, p. 394-412, 2007. - CARD.

KIRSCHBAUM, C. Renascença da indústria brasileira de filmes: destinos entrelaçados? RAE- revista de administração de empresas, v. 46, n. 3, p. 58-71, 2006

KLOTZEL, A. O potencial da indústria cinematográfica no Brasil. Inovação Uniemp, v. 2, p. 18-19, 2006.

LAMPEL, J; SHAMSIE, J. Capabilities in motion: new organizational forms and the reshaping of the Hollywood movie industry. Journal of Management Studies, v. 40, n. 8, p. 2189-2210, dec., 2003.

MANTOVANI, B; MEIRELLES, F; MÜLLER, A. L. Cidade de D eus: o roteiro do filme. Rio de Janeiro: O bjetiva, 2003.

MATTA, J. P. R. Análise competitiva da indústria cinematográfica brasileira no mercado interno de salas de exibição, de 1994 a 2003. 2004. 296 p. Dissertação de Mestrado em Administração, Escola de Administração, Universidade Federal da Bahia, Salvador, 2004.

PETERSON, R. A; ANAND, N. The production of culture perspective. Annual Review of Sociology, v. 30, p. 311-334, 2004. Disponível em: http:// arjournals.annualreviews.org. Acesso em 31.10.2008.

SOUZA, A. P. Teia de números. Carta Capital, São Paulo, ano 10, n. 269, 3 dez. 2003, p. 56-58. 